\title{
Severity stratification of patients hospitalized on the Internal Medicine ward: work in progress
}

\author{
Giuseppe Chesi, ${ }^{1}$ Roberto Nardi ${ }^{2}$ \\ ${ }^{1}$ Department of Internal Medicine Sud Area, AUSL Reggio Emilia; ${ }^{2}$ Internal Medicine, Medical Department, Maggiore Hospital, \\ AUSL Bologna, Italy
}

Amidst the ongoing reorganization of the national health service, there is an ever-greater call for hospital models that are structured on different levels of intensity of care. While these have still not been completely defined, the concept according to which patients are allocated to the best setting of care, tailored to the needs of the clinical complexity of the individual patient, is gradually taking hold. Unfortunately, there is still much confusion over terminology, both in the definition of complexity of care and of intensity of care (defined as the level of care required by the single patient based on a clinical assessment of the instability and complexity of medical and nursing needs) (Table 1), ${ }^{1-3}$ as well as in the definition of the complex, critical, unstable and frail patient. ${ }^{1}$

The different areas of clinical complexity, nursing and management of patients admitted onto the Internal Medicine ward require a multidisciplinary approach and a multidimensional assessment (Table 2).

Scotti and Pietrantonio ${ }^{4}$ offer a number of very interesting insights, emphasizing the specificity, characteristics and strengths of Internal Medicine in the current epidemiological context of hospitalized patients. The stratification of the severity of patients is a subject for debate. Is multi-parametric evaluation through the use of fast and facilitating scores useful to appropriately stratify our patients to the intensity of care they need? ${ }^{5}$ A specific question is whether the modified

Correspondence: Giuseppe Chesi, UOC Medicina Interna Ospedale C. Magati, viale Martiri della Libertà 2, 42019 Scandiano (RE), Italy.

E-mail: chesig@ausl.re.it

Conflict of interests: the authors declare no potential conflict of interests.

Received for publication: 27 August 2013.

Revision received: 30 August 2013.

Accepted for publication: 4 September 2013.

This work is licensed under a Creative Commons Attribution NonCommercial 3.0 License (CC BY-NC 3.0).

CC Copyright G. Chesi and R. Nardi, 2013

Licensee PAGEPress, Italy

Italian Journal of Medicine 2013; 7:231-233

doi:10.4081/itjm.2013.231 early warning system (MEWS) score may be the best tool to establish prognosis. ${ }^{6}$ The MEWS score (and its subsequent amendments) was not really designed to evaluate the severity of patients on admission to the hospital ward, but as a simple tool for a quick clinical assessment of the patients admitted, without any continuous technological monitoring, given that any delay in essential intervention could lead to a rapid decline in clinical condition. ${ }^{7}$ Few studies considered the MEWS score as a means to stratify hospitalized patients either in Internal Medicine and on other specialized wards. In some retrospective studies, cases were divided into classes of severity by calculating the MEWS score only after admitting the patient onto a hospital ward. ${ }^{8,9}$ These papers, although extremely heterogeneous, confirm the report by Scotti and Pietrantronio that a high rate of patients admitted onto Internal Medicine wards have lower MEWS scores, mainly 0-1. The least that could be said, and this is by no means a holistic point of view, is that many of these patients could have been considered suitable for outside hospital care and in several cases this may have been inappropriate. ${ }^{10}$ Beside this, there is the fact that, although MEWS score explores the patient's clinical instability, it is not an adequate tool to assess the complex Internal Medicine patient according to the different domains of complexity. ${ }^{1}$ Another critical issue for MEWS score concerns respiratory rate. Although considered to be the best parameter by which to explore the degree of ventilatory reserve of patients with chronic respiratory diseases ${ }^{12}$ respiratory rate is not usually tested by physicians and nurses on Internal Medicine wards. ${ }^{11}$ As alternative parameters to respiratory rate, the most easily detectable used in Internal Medicine departments are arterial oxygen saturation and $\mathrm{O}_{2}$ therapy. ${ }^{13}$ These were added to the modified ViEWS score (Vitalpac ${ }^{\mathrm{TM}}$ early warning score) ${ }^{14}$ that adopts six parameters compared with the five of the MEWS score. Unfortunately, these scores still have some important intrinsic limitations that can significantly impair the stratification of severity criteria in admitted patients. Two main problems are: i) the fact that the occurrence of a significant hyperpyrexia can have a huge conditioning effect over almost all other parameters, especially in a patient of advanced age; ii) the presence of highly unstable and potentially fatal diseases in patients with a lower MEWS score on admission. It is common to observe that a febrile patient, 
maybe even during a simple viral fever, can develop tachycardia, tachypnea, a decline in $\mathrm{O}_{2}$ saturation, and a reduced level of alertness, which may correspond to a MEWS score of 3 or 4 points. All these parameters, once the patient is no longer febrile, could all be nor$m a l$, therefore leading to a completely different MEWS score, even close to 0 . In order to overcome this problem, some Authors, mostly in Emergency Departments, have suggested another score that, unlike MEWS and ViEWS, does not consider body temperature. The rapid emergency medicine score (REMS), ${ }^{15}$ including 6 items (age, heart rate, respiratory rate, mean arterial pressure, Glasgow coma scale and saturation in arterial $\mathrm{O}_{2}$ ), has not yet aroused much interest in the literature. It avoids a potential confounding factor such as higher body temperature, but introduces age as a parameter. However, given the well-known biological variability among patients, this can become a cause of confusion. Many diseases include a high potential risk of sudden destabilization, such as acute coronary syndrome, acute pancreatitis, digestive hemorrhage, etc. All these situations can present even very low MEWS/ViEWS scores on admission, although they have the potential of quickly degenerating with malignant arrhythmias or otherwise unpredictable shock. The significant influence of body temperature, the presence of clinical conditions themselves likely to result in rapid and dangerous destabilization (regardless of the ViEWS or MEWS score) make these instruments potentially inadequate and a poor replacement for clinical judgment in prognostic stratification. Careful monitoring, especially in the early stages, is, therefore, required. Obviously, we can not abandon useful technologies, such as multi-parametric monitoring and some other tools, in appropriate care settings. ${ }^{16,17}$ Probably the most effective method for monitoring our patients is clinical observation, repeated several times throughout the day, ${ }^{7}$ according to the main diagnosis and/or problem on admission. More studies are needed to collect additional data in order to determine whether and how some surrogate scores can really help in supporting clinical judgment in order to allocate the patient to the most appropriate care setting in a hospital system structured on different levels of intensity of care. ${ }^{20,21}$ For the mo-

Table 1. Stratification for levels of intensity of care and complexity of care.

Intensity of care $^{2}$
Assign the patient a bed in the most appropriate care setting, according to
his or her care requirements, linked not only to the need for hospitalization,
but also to current medical condition and the need for instrumental
monitoring

\section{Complexity of care $^{3}$}

The overall performance of medical and nursing assistance related to the different domains of care, in terms of intensity of commitment, time and quantity and/or quality of the work of all professionals involved

Table 2. Domains of complexity in patients admitted onto Internal Medicine wards.

\begin{tabular}{|c|c|c|}
\hline Clinical complexity & Nursing clinical care complexity & Management complexity \\
\hline Disease severity/staging & Breathing & Anxiety, fear \\
\hline Clinical instability & Nutrition and hydration & Poor compliance \\
\hline Atypical clinical symptoms and signs & Urinary and fecal elimination & Poor collaboration \\
\hline Diagnostic challenge & Hygiene & Difficult communication \\
\hline Rare disease & Movement & Social isolation \\
\hline Multiple active disease & Rest and sleep & Loneliness, widowhood \\
\hline Biological frailty & Cardiovascular function & Social network \\
\hline High risk of $\mathrm{ADR} / \mathrm{ACE}$ & Safe environment & Family stress \\
\hline Cascade events & Interaction and communication & Recent discharge \\
\hline Failure to thrive and related syndromes* & Advanced wound dressings & Frequent users \\
\hline Complex procedures & Therapeutic procedures & Functional dependence \\
\hline Complex therapies & Diagnostic procedures & Risk of falling \\
\hline Monitoring & Monitoring & Cognitive dysfunction \\
\hline Devices and instrumental management & Devices and instrumental management & Polypharmacy \\
\hline \multirow[t]{5}{*}{ Follow-up needs and checkups } & & No. of healthcare providers \\
\hline & & Coordination of care \\
\hline & & Decision making \\
\hline & & Continuity of care \\
\hline & & Difficult discharge \\
\hline
\end{tabular}

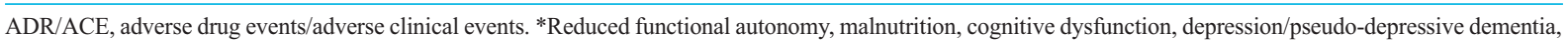
falls, delirium, etc. 
ment, we can only conclude that MEWS and ViEWS scores can be usefully employed on Internal Medicine wards as a rapid alert system, particularly by the nursing staff. ${ }^{22}$ The debate and reports on this topic published in recent years in the literature has focused the attention of the medical community on the need to build simple, easily applicable tools to assess the patient who is potentially critically ill. These tools should promote provision of the appropriate intensity of monitoring and level of care to meet the patient's real needs. ${ }^{20}$ This is a challenge for the future in which the Internal Medicine physicians, according to their wider view of the problems involved and their ability to synthesize the essential issues in a complex context, can select the priorities without abandoning the technology, and will have an increasingly important role. ${ }^{23}$ This will be facilitated by building patient-centered organizational models, such as those based on the intensity of care. The high intensity areas of care, recently better defined in official documents for the accreditation of Internal Medicine wards in the Emilia Romagna (northern Italy) Healthcare Service, ${ }^{17}$ may be the most appropriate and cost-effective care setting for the complex patients who are most often elderly with multiple comorbidities, with significant degrees of instability, and who are not yet eligible for admission to the Intensive Care Unit.

\section{References}

1. Nardi R, Berti F, Greco A, et al. Complexity in hospital internal medicine departments: what are we talking about? Ital J Med 2013;7:142-55.

2. Briani S, Cortesi E. L'ospedale per intensità di cure: aspetti teorici e problemi aperti. Igiene e Sanità Pubblica 2007;63:577-86.

3. Moiset C, Vanzetta M. Misurare l'assistenza - il SIPI: dalla progettazione all'applicazione. Milano: Mc GrawHill; 2009.

4. Scotti E, Pietrantonio F. The hospital Internal Medicine specialist today: a literature review and strength, weaknesses, opportunity, threats (SWOT) analysis to develop a working proposal. Ital J Med 2013;7:278-86.

5. Heitz CR, Gaillard JP, Blumstein H, et al. Performance of the maximum modified early warning score to predict the need for higher care utilization among admitted emergency department patients. J Hosp Med 2010;5: E46-52.

6. Burch VC, Tarr G, Morroni C. Modified early warning score predicts the need for hospital admission and in hospital mortality. Emerg Med J 2008;25:674-8.

7. Ludikhuize J, Smorenburg S, de Rooij S, de Jonge E. Identification of deteriorating patients on general wards; measurement of vital parameters and potential effectiveness of the Modified Early Warning Score. J Crit Care 2012;27:424.e7-13.

8. Bollini G, Colombo F. L'intensità assistenziale e la com- plessità clinica: un progetto di ricerca della Regione Lombardia. Milano: Era Futura; 2011. Available from: http://www.era-futura.com/wordpress/wp-content/ uploads/2012/02/Intensit\%C3\%A0-Assistenziale-e-laComplessit\%C3\%A0-Clinica.pdf

9. Robb G, Seddon M. A multi-faceted approach to the physiologically unstable patient. Qual Saf Health Care 2010;19:e47.

10. Joynt KE, Lha AK. Perspective path forward on medicare readmissions. New Engl J Med 2013;368:1175.

11. Ludikhuize J, de Jonge E, Goossens A. Measuring adherence among nurses one year after training in applying the modified early warning score and situation-background-assessment-recommendation instruments. Resuscitation 2011;82:1428-33.

12. Yañez AM, Guerrero D, de Alejo RP, et al. Monitoring breathing rate at home allows early identification of COPD exacerbations. Chest 2012;142:1524-9.

13. Hammond NE, Spooner AG, Barnett AG, et al. The effect of implementing a modified early warning scoring (MEWS) system on the adequacy of vital sign documentation. Austr Crit Care 2013;26:18-22.

14. Kellett G, Woodworth S, Wang S, Huang W. Changes and their prognostic implications in the abbreviated Vitalpac $^{\mathrm{TM}}$ early warning score (ViEWS) after admission to hospital of 18,853 acutely ill medical patients. Resuscitation 2013;84:13-20.

15. Bulut M, Cebicci H, Sigirli D, et al. The comparison of modified early warning score with rapid emergency medicine score: a prospective multicentre observational cohort study on medical and surgical patients presenting to emergency department. Emerg Med J 2013. [Epub ahead of print].

16. Churpek M, Yuen TC, Edelson DP. Risk stratification of hospitalized patients on the wards. Chest 2013;143: 1758-65.

17. Agenzia Sanitaria e Sociale Regionale Emilia Romagna. Requisiti specifici per l'accreditamento delle strutture di medicina interna; Oct 2011. Available from: http://assr.regione.emilia-romagna.it/it/servizi/pubblicazioni/legislazione-e-atti-amministrativi/requisitiaccreditamento/requisiti-specifici

18. Fullerton J, Price CL, Silvey NE, et al. Is the modified early warning score (MEWS) superior to clinician judgement in detecting critical illness in the pre-hospital environment? Resuscitation 2012;83:557-62.

19. Sevransky J. Clinical assessment of hemodynamically unstable patients. Curr Opin Crit Care 2009;15:234-8.

20. Chesi G, Boni F. Ospedali e modelli organizzativi per intensità di cure: il punto di vista dell'internista. Ital J Med 2012;6:63-71.

21. Nardi R, Arienti V, Nozzoli C, Mazzone A. Organizzazione dell'ospedale per intensità di cure: gli errori da evitare. Ital J Med 2012;6:1-13.

22. Prytherch DR, Smith G, Schmidt PE, Featherstone P. ViEWS-Towards a national early warning score for detecting adult inpatient deterioration. Resuscitation 2010;81:932-7.

23. Nardi R, Mathieu G, Berti F, et al. Evaluation models and items of clinical competence for the hospital physicians in internal medicine. Ital J Med 2011;55:S3-13. 